\title{
Identity Construction of Emeyode Ethnic Group (The Relationship of Sago and Emeyode Ethnic Group in South Sorong Regency, West Papua Province)
}

\author{
Adolof Ronsumbre \\ \{ronsumbreadolof@gmail.com\} \\ Anthropology Department, University of Papua
}

\begin{abstract}
Sago palm area in Indonesia is approximately 5.5 million hectares, and approximately 5.2 million hectares of sago palms are found in Papua and West Papua Provinces. West Papua Province has the largest area of sago plants in Indonesia with an area of approximately 4,749,424 million hectares, and South Sorong Regency in particular is an area that has the largest area of sago plants in the province. Of the area of sago forest in West Papua Province 510,213 , South Sorong Regency has the largest sago forest with 148,004 , or approximately $29 \%$. Based on the facts above, this study aims to explore the local community knowledge about the relationship between sago palms and the Emeyode ethnic group; and describes the construction of Emeyode ethnic group identity through sago. Answering the research questions, the research method used is the ethnographic method. The characteristic of the ethnographic method is participant observation, by observing directly the sago plants, and the Emeyode ethnic group in terms of its relation to sago. The interview method is used to uncover the relations of sago with the Emeyode ethnic group. As a result, it shows that there is a relationship between sago plants and the Emeyode ethnic group in terms of cultural values. Specifically, sago is perceived as a gift from the "giver" to the Emeyode ethnic group as a source of food, as well as a symbol of the construction of the Emeyode ethnic group's identity. Therefore, maintaining and preserving sago plants means protecting the life of the Emeyode Ethnic Group.
\end{abstract}

Keywords- Sago, Relationship, Ethnic Group, Identity

\section{Introduction}

In 2015, it was a valuable time for writer to visit a new area to begin the research. At that time, it was for the first time the writer visited and conducted research in the Kokoda District area of South Sorong Regency, West Papua Province. The trip starts from Manokwari Regency to Teluk Bintuni Regency using four-wheeled vehicle transportation (Hilux) and takes 7-8 hours. The trip continues from Teluk Bintuni Regency to South Sorong Regency using speed boat sea transportation and takes about 4 hours. Arriving at Tarof Village, Kokoda District, South Sorong Regency, the writer met with the Emeyode ethnic group who were preparing 
traditional technology to go to the sago hamlet to cultivate sago palms. On the other hand, the writer saw someone selling sago, packed in a container, called keiyate in local terms, and also saw the construction of house buildings made from sago plant raw materials. This fact shows that the Kokoda District is identical with sago plants.

The potential of sago in the Kokoda District area was once documented by Prof. Dr. Barahima in his paper [1]. One of the sub-chapters discusses the potential of sago in the South Sorong Regency. He stated that in the world, there were 2,250,000 sago forests, and 224,000 sago gardens. While, in Indonesia, it is estimated to have 1,250,000 hectares of sago forest, and 148,000 hectares of sago gardens. In Papua, in particular, it is estimated that there are 1,200,000 hectares of sago forests, and 14,000 hectares of sago gardens. Meanwhile, the total area of sago forests in the South Sorong Regency reached 311,591 Ha, or around $44.88 \%$ of the total area of South Sorong Regency, or about $25.96 \%$ of the total area of sago in Papua. This fact shows that in Indonesia, especially in Papua, the largest sago forest is in the area of South Sorong Regency, West Papua Province. This phenomenon shows that the South Sorong Regency of West Papua Province is blessed with a wealth of biological resources producing high carbohydrates, namely sago, which is very abundant.

The existence of sago plants from traditional to modern contexts cannot be separated from the ability of Emeyode ethnic group in their efforts to preserve and protect sago plants. This ability gives the fact that there is a strong relationship between the Emeyedo tribe and sago plants. Sago plants are maintained and preserved by the Emeyode ethnic group due to their relations. The relationship between the Emeyode ethnic group and the sago plants gave birth to the construction of the Emeyode ethnic identity through sago. Based on this phenomena, this study aims to explore the local community knowledge about the relationship between sago palms and the Emeyode ethnic group; and describes the construction of Emeyode ethnic group identity through sago.

\section{Method}

The essence of a research is answering research questions. Therefore, to answer the research questions, a number of scientific methods are used. The stages of the methodology carried out in this study include: (1) selecting research location, (2) finding informants, (3) collecting and recording field data, (4) classifying, identifying and analyzing all field data, (5) writing a research report, [2]. The location of the research are Kampung Tarof, Negeri Besar, Topdan, Dauban, and Migirito in Kokoda District, South Sorong Regency, West Papua Province. This location is an area that has abundant of sago palm plants. This research location is categorized as an outsider location, in which the research location is outside the area of the researcher. In other words, the researcher examines the phenomenon of ethnicity and culture outside the ethnic and cultural group of the researcher.

The determination of the informants is done by selecting key informants. A key informant is someone who has relatively complete information on the culture under study,. Referring to [2], one thing that needs to be considered in choosing key informants is people who have had informal experience for years. In this context, the key informants have 2 main elements, namely: knowing and experiencing the phenomenon studied by the researcher. Therefore, the key informants determined were the head of the village, the head of the clan, the head of the sago hamlet, and the sago farmers. The primary data of the study is the relationship between sago plants and the Emeyode ethnic group. The preliminary observation of the location of 
research and culture as well as the Emeyode ethnic group was conducted before going to the research field by obtaining information from several lecturer colleagues who have researched in the area, and seeking information through University students who come or originated from the location of the research. In addition, the writer also read several written reports about the location of the research.

In this study, the data were obtained through the method of observation, unstructured interview and in-depth interview. For the observation phase, it started when the researcher enters the research location using speed boat sea transportation. Observation was also made when arriving at the research location. The focus is on the community activities related to sago. An in-depth interview was conducted by the researcher to collect the data as follows:

First, qualitative data and quantitative data about sago plants. Quantitative data were obtained through statistical data that had been published by previous researchers, while qualitative data on the concept of sago were obtained through interviews with the informants. Second, the data on who the Emeyode ethnic group is and what are the clans categorized as the Emeyode ethnic group. This data was obtained by the writer through in-depth interviews with key informants at the research location. Third, data on cultural values or cultural concepts about sago plants and their relationship with the Emeyode ethnic group? This data was obtained by the writer through in-depth interviews with key informants at the location of the research. After all the data has been collected through the method of observation, unstructured interview, indepth interview with key informants, literature review, then it proceeds with the process of analyzing data using theories. The use of theory is aimed at portraying holistically and comprehensively or a kind of "deep painting", of the Emeyode relations through sago, which in turn makes the construction of Emeyode ethnic identity.

\section{Result and Discussion}

Initially, with the spirit of searching for new territories to be made as ownership territories for the benefit of settlements, then came 22 small groups that mentioned their names as, Agia, Angiluli, Biawa, Birawako, Beyete, Damoi, Derago, Gogoba, Irewa, Imo, Jare, Maratar, Mudaye, Nawari, Tayo, Tamar, Turae, Tobi, Tameye, Totaragu, Ugaya, Ugaje. The decision of these 22 groups to stay and settle in the area which is now called Kokoda District, South Sorong Regency, West Papua Province, one of the reasons is, for the interest in the views of sago plants which are very abundant, although the meaning and function of sago plants is not yet understood. Through the trial and error method, it turns out that sago plant has function as a food source and almost becomes a staple food. The areas covered by sago plants were chosen as settlement locations. These 22 groups live in the area of their respective sago hamlets while maintaining their respective group names. In subsequent developments, there is an awareness of a threat to their territory, which is a source of food for humans. What they have in the mind is the presence of other groups to seize power over the region. This awareness awakens a sense of unity. These 22 groups then integrated into one group which called themselves the Emeyode ethnic group. This kind of mergers or integration is a bond to face the challenges from outside [3]. The integration of the 22 groups into one ethnic group called Emeyode, is only driven by the spirit of external threats. In addition, these 22 groups come from different regions of origin. It means that the history of the origin of these 22 groups varies. From the naming point of view, these 22 groups are certainly different. Therefore, when their presence in a new region, at least they construct a new identity that is adapted to the ecological conditions of the final 
migration area, so that they are categorized as indigenous tribes because they are identical with ecological conditions.

What is said by Ken Plumer is true [4]; identity is the process of naming or placing oneself in a particular category or social construction. This means that, when the Emeyode ethnic group is in a new territory, then they construct a new identity so that their position is included in a category as a native ethnic group. The construction of the identity or naming of the Emeyode ethnic group is originated from the inspiration of sago plants. The talk about the Emeyode ethnic group cannot be separated from sago plants. Sago plants are Emeyode ethnic groups, and Emeyode ethnic group is sago plants. This phenomenon gives us an understanding that there is a relationship between sago palm plants and the Emeyode tribe.

The relationship between sago plants and the Emeyode ethnic group may not happen directly, but through their concept of sago. The question is what are the cultural values as the basis for the relationship between sago plants and the Emeyode ethnic group? The relationship between sago plants and the Emeyode ethnic group began since the first arrival of the Emeyode ethnic group in what is now called Kampung Tarof, Kokoda District. The first impression of a sago plant is that it is not possible for a sago plant to just appear, there must be a creator, and there must be a giver. The abundant sago plants are gifts from the giver. The name of the giver is very sacred. To say the name of the giver means to bring customary sanctions from the giver. The relationship between the giver and the recipient of the sago plant is not just about giving and receiving. It means that since the giver has given the sago plants, so that it must be accompanied by the compensation of the recipients to the giver.

The rewards that should be given by the Emeyode ethnic group as the recipients are that the Emeyode ethnic group must maintain or preserve the sago plants, because keeping sago is like keeping life. The concept of keeping sago, preserving life is the cornerstone of the Emeyode ethnic group in producing local wisdom or in terms of Clifford Geertz [5], he calls it local knowledge. Sago plants are the inheritance of givers to the Emeyode ethnic group, so sago plants must be maintained and preserved.

The concrete forms of relations between sago plants and the Emeyode ethnic group, which eventually became the basis for the construction of the Emeyode ethnic group identity is as follows: First, the naming of the Emeyode ethnic group. Etymologically, the term emeyode consists of two words Eme and Yode. Eme means let's, while Yode means we walk. So, Emeyode means let's walk. In the context of Emeyode, let's mean walking but not alone, but walking together. It means that the 22 clans must walk together.

Sago plants grow in a large area, growing together in clumps or a kind of group. It means that the group of sago plants settled and did not move. So, the name of the Emeyode ethnic group is an ethnic group that lives in the same area, namely Tarof Village, Topdan Village, Besar Negeri Village, Dauba Village, then they must go together. Because the Emeyode ethnic group is a group of people, so they can move. Meanwhile, sago plants live in the same area, Kampung Tarof, Topdan, Negeri Besar, Dauba. The concept of values of togetherness becomes a unique cultural pattern and controls the social behavior in the Emeyode ethnic group.

Second, as a source of local food for the life of the Emeyode ethnic group, the 22 clans have their own sago hamlet. All sago hamlets are named by each of the clan or the owner. Sago hamlet boundaries between clans are marked by planting a type of sago plant called sago mola. The traditional organization or traditional leader who is given the responsibility as the regulator of the sago hamlet is the head of the sago hamlet. Third, as an effort to protect the sago hamlets belonging to the 22 clans of the Emeyode ethnic group, they have designated all sago hamlet areas as sacred. The question is why is that area categorized as a sacred area? Adopting the theory proposed by [6], who said that sacredness always manifests itself as a reality that is 
entirely different in level from "natural" realities, (Eliade, 2002: 2). This means that, the level of the sago hamlet area is different from other regions. On the land that is now the sago hamlet area, the giver gives the sago plant to the recipient of the Emeyode ethnic group as one of the traditional food sources. Without food, maybe we could become extinct in the past. In the local terms, in terms of the sacred area, there is a traditional saying that is well known, related to the giver and the recipients, which reads: later our ancestors will be angry, then the people will be hit by the rain and flood.

\section{Conclusion}

Based on the analysis above, it can be concluded that the relation between sago palms and the Emeyode ethnic group, was happened not directly, but there was an intermediary, namely culture. The cultural values were: 1) Sago is a gift from the giver to the recipient of the Emeyode ethnic group. 2) Sago is a traditional to modern food source. 3) Sago is an inspiration for the construction of the Emeyode ethnic group identity. 4) Keeping sago means keeping life.

\section{References}

[1] A. Barahima, "Potensi Sumber Daya Sagu Dan Budidayanya di Tanah Papua," Makal. Semin. Nas. Pengemb. Sci. Park Bid. Fokus Sagu di Provinsi Papua Barat, 2018.

[2] J. Spradley, Metode Etnografi. Yogyakarta: Tiara Wacana, 2006.

[3] A. Lapian, "Memperluas Cakrawala Melalui Sejarah Lokal," J. Prism., vol. 8, 1980.

[4] P. P. Laksono and Dkk, Permainan Tafsir, Politik Makna di Jalan Pada Penghujun Orde Baru. Yogyakarta: Insist Press, 2000.

[5] C. Geertz, Pengetahuan Lokal. Yogyakarta: Rumah Penerbitan Merapi, 2003.

[6] M. Eliade, Sakral dan Profan. Yogyakarta: Fajar Pustaka Baru, 2002. 